\title{
A Defence on the Prominence of Rational Actor Model within Foreign Policy Analysis
}

\author{
Sadra Shahryarifar \\ University of St Andrews, Scotland, UK
}

\section{Introduction}

"That rational and most excellent work of nature, Man" (Hobbes, 1997: 81). This is how Hobbes bases his introductory account on the creation of the Commonwealth. A politics founded upon rationality and thus an unnatural product of man. Years later this principle came to underpin the mainstream school of thought in International Relations (IR) i.e. the classical Realism. As a subfield of IR, Foreign Policy Analysis (FPA) reflected the assumptions of classical Realism into an analytical theory known as Rational Actor Model (RAM). While limitations to the human rationality in the process of decision-making contested its applicability to international politics, it still remains a fundamental analytical tool. In fact, it can be a powerful analytical model only if the scholarship correctly appreciates its theoretical ground. Knowing what the theories are for, and how they are supposed to be applied are necessary prerequisites to their proper efficacy as helpful analytical tools. That is to say, if RAM had not wrongly been applied to the problems, it would not have misguided the FPA theorists.

This paper's purpose is to offer a conceptual breakthrough on RAM so as to enhance its ability in a way that will let analysts to accommodate some of the anomalies into the theoretical ground of RAM, without greatly undermining its validity. Such precaution is necessary to take because admittedly, RAM's continual prominence within the discipline owes much to its explanatory power as a valid analytical tool, without which the whole notion of rationality in politics would be called into question. To accomplish the task, first, I shall examine RAM as a predictive model of action.Later, by analysing the nature of explanans in IR, I shall discuss the mission of theories in perceiving of social science problems with a view to reinterpret RAM as an integrate-able model of analysis. 


\section{RAM as a model}

To make sense of foreign policy actions, FPA models attempt to explain how and why a key policy is adopted. As one such model, RAM seeks explanation for foreign policy outcomes or the 'events'; this must be contrasted to the study of foreign policy 'processes' (Allison et al., 1999: 13). 'Events', as Hudson remarked, consist of what actually happened, and how they did happen so (Hudson, 2005: 9). Accordingly, 'events' are the subject of analysis of RAM. In this theory, it is assumed that choice is made by a recourse to a rational procedure. And that actions are the products of careful calculations in that procedure.

The decision-making procedure, according to RAM, involves four main stages (Heywood, 2014: 134). The first step is to identify the problem. That is to make meaning out of a complex shapeless reality. For meanings do not exist per se, rather they are subjective interpretations of objective facts. To comprehend this better, for instance, consider Iran's possession of the nuclear technology as a fact. How her neighbours make meaning of this fact is up to their interpretations which will determine their positions towards this fact. One such a meaning could theoretically vary on a continuum from perception of an absolute insecurity to pure security. The answer to their positions lies not in the crude fact itself, but in the complex of circumstances involved. Secondly, the preferences of expected foreign policy outcomes have to be ranked orderly. That is the very simple logic which expects a rational actor to order his goals in a way that:

$$
\begin{gathered}
\text { if ' } A \text { ' is preferred over ' } B \text { ' } \\
\text { and ' } B \text { ' over ' } C \text { ', }
\end{gathered}
$$

then 'A' is preferred over ' $C$ ' (Stein, 2012: 131).

Translating ' $\mathrm{A}$ ', ' $\mathrm{B}$ ' and ' $\mathrm{C}$ ' with foreign policy options, a decision making entity would not be rational if, to exemplify, it were to prefer diplomacy over economic sanctions and economic sanctions over military engagement while preferring military choice over diplomacy. Thirdly, a thorough assessment on the consequences of available options must be carried out. This can be an actual research or alternatively a thought experiment in which a logical 'flow of events' are imagined. An example of the latter would be the Prisoner's Dilemma where the rational choice of either actors depends upon the expected rationale of the other. Finally, a rational choice must be that would "reflect mostly preferred consequence among ranked goals" (Allison et al., 1999: 18). 
Built on a Hobbesian account of politics (ibid: 17), RAM does not take normative constraints to be a factor of the decision-making equation. Decisions are made only with regard to goals. Rationality entails that the decision makers make decisions in such a way to maximise their expected utility (Nau, 1998: 2). This means that both pros and cons are taken into consideration in the decision-making procedure. It is not difficult to see how different decision-makers can have different preferences in different orders. Accordingly, aggregating individual preferences (Stein, 2012: 143 ) is devoid of rationality, because rationality is defined only with regard to an individula's specifically determined preference. As a result, RAM would essentially become a reductionist theory (Hees, 1997: 51), meaning that individuals are conceived as the primary agents. In this model, policies are adopted because of rational calculations of an individual human actor.

\section{Limitations of RAM}

With the above account one can easily pinpoint basic limitations to RAM. Most notably, many foreign policy events are the result of consensual decision-making. These are sometimes legally included in decision-making systems at both domestic and international level of decision-making. For instance, in Article 27 of United Nations Charter, the decisions of Security Council "shall be made by an affirmative vote of nine members including the concurring votes of the permanent members" (UN Charter). Likewise, decisions made in parliamentary systems fall under the category of consensual decision-making too. It follows that in all non-individual decision-making systems RAM is an inapplicable model of analysis.

Furthermore, even if decisions are exclusively made by individuals, the model can still give false predictions. Advancements in psychology and neuroscience have revealed limitations to human rationality. In order to function properly, RAM requires rational human actors. In contrast, human decision-making is found prone to deviations from rational procedure. One such psychological source of deviation is the loss aversion (Stein, 2012: 139). This is a condition in which the decision maker accepts greater risks in bad situations than he normally does "when things are going well" (ibid). A good example would be Hitler's decision to invade the Soviet Union. He did only make this detrimental decision when he failed to convince the English into peace. Other psychological deviations include a tendency for simplification of complex reality, and the desire to keep beliefs consistent vis-avis contradictory evidences (Stein: 139). In terms of neuroscience, emotions are the overriding obstacle to rationality. Neuroscience studies unveil how emotions precede reason. Indeed, it is found that every rational thought is first processed in 
the emotional brain or the Limbic System to find its relation with the organism's survival (McDermott, 2004: 693). Those feelings like pride, dignity, fear, greed, jealousy and so forth are all paradigms of emotions that influence the cognitive brain. Returning to the same example, Hitler's greed for extraterritorial expansionism might, conceivably, have inhibited him from rational calculation of the consequences of his decision to attack the Soviets.

\section{The nature of theories}

Looking on the above examples, RAM would have predicted results contrary to the 'events'- i.e. what actually happened and how? And so far it has failed as a reliable predictive model of analysis. What has gone wrong? Below, it will be argued that because of the nature of explanans in social science, theories are more than predictive models. The expectation of giving law-governed relationships would bea wrong starting point to the understanding of IR.

Law-governed systems give consistent results under homologous conditions. When we model predictive theories in scientific studies we look for generalisations that lead to consistent laws. In science the explanan is the structure that determines the consistent outcomes. Structural determinism refers to the idea that social science can be studied by finding law-governed relationships. In fact, such approaches were earlier made by making use of computerised decision aiders to generalise the 'events' into grand foreign policy theories (Hudson, 2012: 29). Expectedly, the results turned incoherent (ibid). In contrast, the omnipresence of structure and agency constitute the explanans of social science (Carlsnaes, 1992). It is intuitively conceivable that structures determine actions and that those actions will form the future structures, and that this chain continues to infinity (Fig1) (ibid: 260). Social theories are developed to explain the links between the structures to agents and vice versa. Different theories reveal different aspects of the same reality. In this sense, antithetical political theories are not contradictory ones. For example, neorealism's structural explanation for the nuclear proliferation does not have to falsify RAM's agent-based explanation. Rather, they may both give true insights into the same reality. Therefore, best analyses are the ones that integrate insights from different theories that explain the role of both structures and agents. Even though an expectation for the possibility of law-like predictive theories in politics is to confuse the nature of explanans in social theories with that of the scientific laws.

If theories are expected to explain different aspects of complex reality, a powerful model is the one that can be integrated with others. To make meaning of foreign 
policy, FPA theories offer actor-specific solutions where individuals are the primary agents. In contrast, IR offers actor-general theories (Hudson, 2005: 1) that generally favour the structural side of foreign policy. Therefore, IR and FPA effectively share their explanandum. A comprehensive analysis must take as much of the Structure-Agency spectrum as possible into consideration. In such a way, integration of IR with FPA gives rise to the critical Foreign Policy (FP) that takes account of both the structure and the agency (Smith et al., 2012: 6). RAM is a powerful explanatory model because its theoretical ground allows its incorporation into structural theories of IR. Bridging the IR-FPA gap, RAM allows the decisionmakers to develop strategic plans of action. In Down's wording we may ask "What would actually happen if men...behave rationally?"(Down, 1957: 19). Thereafter, hypothetical thought experiments can be designed to reciprocate the other player's best choice appropriately. In this way, RAM yields IR with creativity for human action (Hudson, 2005: 4). But why and how RAM can be integrated with IR? Before going to answer this question first we explain why sometimes RAM had given false analytical predictions.

False predictions arise from incorrect application of theoretical models into realworld problems. Misleadingly, this will cause the theory to look like an invalid model of analysis. As Wohforth argued, however, in essence each theory is composed of three constituent components.These components include assumptions, scope conditions and predictions (Wohlforth, 2012: 41). If the assumptions are proven wrong then the theory is falsified. For it would suggest that the theory was incompatible with reality. However, correct assumptions are not solely enough to yield realistic predictions. Rather, a theory is only capable to predict in specified circumstances. We call these circumstances the scope conditions of the theory. False predictions occur when analysts confuse assumptions with scope conditions of a theory. In the case of RAM, it is assumed that the actor is a self-interested individual agent. Its predictions in a hypothetical scenario would be a particular decision or foreign policy outcome. However, it is important to notice that it is not assumed the actor is rational. Rather, rationality is the scope condition of the RAM theory. It follows that RAM is only applicable to problems wherein the actor is rational and has received full information for processing. Applying RAM otherwise would be the main pitfall that would cause RAM to look like an invalid analytical tool.

\section{The conceptual breakthrough}


In RAM, rationality is the means to aspire to the goals. However, since rationality does not define the goals in the first place the goals are left unexplained (Carlsnaes, 1992: 251). This characteristic is the conceptual breakthrough that allows integration of RAM with structural IR. Indeed, the goals in RAM can be the product of structures. This model is diagrammatically represented to show how the structure and agency can be linked in RAM (Fig 2). That the analysis of a foreign policy 'event' starts off by exploring the rationale behind. Then, in order to make sense of the 'events', structural factors are used to understand the goals of the actor. Accordingly, the goals, themselves, no matter how non-utilitarian can never be irrational. Nonetheless, it must be noted that the Structure-Agency dichotomy is not resolved since the proposed model is still a bottom-up relationship in which the structure is privileged to be the ultimate determinant of choice (Carlsnaes, 2012: 126). In this way, neuroscientific and psychological deviations do not undermine RAM's credibility insofar as they influence the goals of the decision-makers.

To show how, let us consider the Anticipated Emotion as one such psychological deviations. It suggests that emotions make us to decide on choices that maximise our happiness (McDermott, 2004: 698) while rationality entails the adoption of choices that maximise utility. For a human actor a smaller loss when a greater one was anticipated is more rejoicing than a smaller gain when a larger one was expected. If the actors in the RAM theory were assumed utility maximisers this deviation would falsify the theory. The trick is to replace the economic theory of utility for the psychological theory of Anticipated Emotion so that the emotions determine the unexplained goals of the actor. If, as we suggested above, the impossibility of having irrational goals holds true, non-utilitarian decisions would not be necessarily irrational ones. It must be clear that RAM is flexible to accommodate similar anomalies into its theoretical ground.

\section{Conclusion}

In conclusion, RAM continues to remain a prominent mainstream theory of FP because, as a theory, it has powerful explanatory potential. It is important to recall that social theories must not be applied to cases as though they are predictive laws. Rather, they are supposed to be understood as useful analytical tools that help analysts to gain better insights. Thereby, RAM is a very powerful analytical theory despite having serious limitations as a predictive model of action. Incorporating insights from different theories reveals a clearer vision of the complex reality. RAM is a powerful explanatory tool because, if correctly understood and appropriately applied, it can be integrated with structural theories of IR. We have 
shown that a modified account on assumptions, scope conditions and predictions of RAM is capable of encompassing, in part the Agency-Structure, psychological and neuroscientific dimensions of the complex reality.

\section{Figure 1:}

Action1

Structure1

Action2

$\sum_{\text {Time }}^{\text {Action2 }}$

Figure 2:
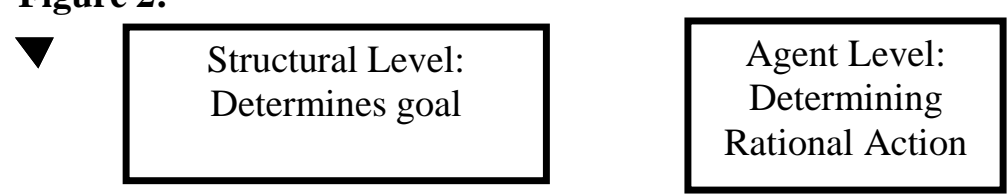

\section{Analysis}

\section{References and notes:}

-Allison, G, Zelikow, P, Essence of Decision: Explaining the Cuban Missile Crisis (New York: Pearson, 1999).

-Carlsnaes, W, 'Actors, Structures, and foreign policy analysis', in Smith, S, Hadfield, A, Dunne, T (eds.), Foreign Policy Theories, Actors Cases (Oxford: Oxford University Press, 2012), pp. 113-129.

-Carlsnaes, W, 'The Agency-Structure Problem in Foreign Policy Analysis' in International Studies Quarterly, Vol. 36, No. 3 (1992), pp. 245-270.

-Hees, M.V 'Explaining institutions: A defence of reductionism' in European Journal of Political Research, Vol. 32, No. 1 (1997), pp. 51-69.

-Heywood, A, Global Politics (Houndmills: Palgrave Macmillan, 2014).

-Hobbes, T, 'Leviathan' in Cahn, S.M (ed.), Classics of Modern Political Theory (New York: Oxford University Press, 1997).

-Hudson, V.M, Foreign Policy Analysis: 'Actor-Specific Theory and the Ground of International Relations' in Foreign Policy Analysis, Vol. 1, No. 1 (2005), pp. 1-30.

-Hudson, V.M, 'The history and evolution of foreign policy analysis', in Smith, S, Hadfield, A, Dunne, T (eds.), Foreign Policy Theories, Actors Cases (Oxford: Oxford University Press, 2012), pp. 13-34. 
-McDermott, R, 'The feeling of Rationality: The Meaning of Neuroscientific Advances for Political Science', in Perspectives on Politics, Vol. 2, No. 4 (2004), pp. 691-706.

-Smith, S. Hadfield, A. Dunne, T. 'Introduction', in Smith, S, Hadfield, A, Dunne, T (eds.), Foreign Policy Theories, Actors Cases (Oxford: Oxford University Press, 2012), pp. $1-9$.

-Stein, J.G, 'Foreign policy decision making: rational, psychological, and neurological models', in Smith, S, Hadfield, A, Dunne, T (eds.), Foreign Policy Theories, Actors Cases (Oxford: Oxford University Press, 2012), pp. 130-146.

-Wohlforth, W.C, 'Realism and foreign policy', in Smith, S, Hadfield, A, Dunne, T (eds.), Foreign Policy Theories, Actors Cases (Oxford: Oxford University Press, 2012), pp. 35-53.

Online Sources:

-Downs, A, An Economic Theory of Democracy (1957) accessed at http://web.posc.jmu.edu/seminar/readings/1c-rational\%20choice\%20model/downs.pdf.

-Nau, R.F, Arbitrage, Incomplete Models and Interactive Rationality (1998) accessed on $22 / 02 / 2015$ http://www.ibrarian.net/navon/page.jsp?paperid=17788754\&searchTerm=prospect+t heory+an+analysis+of+decision+under+risk.

-The United Nations Charter accessed on 22/02/2015 at http://www.un.org/en/documents/charter/chapter5.shtml.

\title{
Summary
}

\section{A Defence on the Prominence of Rational Actor Model within Foreign Policy Analysis}

\author{
Sadra Shahryarifar \\ University of St Andrews, Scotland, UK
}

Rational Actor Model (RAM) has continued to be a powerful explanatory theory of foreign policy analysis. Even though, limitations on the human rationality in decision-making place restrictions on its validity as a predictive model of analysis. These limitations mainly arise from false expectations from RAM as an analytical tool. Reinterpreting the mission of theories in social science would address the drawbacks associated with such false expectations from theories. A conceptual breakthrough is discussed that allows RAM to overcome the limitations upon its validity. This discussion argues on the appropriate application of RAM onto real world problems which would open space for the integration of RAM into other IR-FPA theories.

Keywords: RAM, FP theory, decision-making, rational theory, analytical tool, utilitymaximiser 